\title{
PROJECT RISK PRIORITIZATION USING AN EXPERT CHOICE MODEL
}

\author{
Scott Serich and Christine Xiaoyi Dai \\ Project Management Program, Management Science Department, The George Washington University \\ 2101 F. St. NW, Bldg. AL, Room 301, Washington, DC 20052 \\ serich@acm.org, cdai@gwu.edu
}

Compared to their functional-management counterparts, project managers are often expected to command a much broader range of management and decision-making skills. Complex decisions must be made across the entire project life cycle (Project Management Institute Standards Committee 1996), from initial evaluation and selection, to staffing and risk quantification during the planning phase, to auditing and acceptance during closeout. Mian and Dai (1999) demonstrate the use of Expert Choice® (Forman et al, 1996) to assist project selection, bid evaluation, schedule compression strategy, evaluation of ongoing projects, and selection of a project manager.

Expert Choice is a robust, user-friendly tool that can help facilitate project decisions by reducing the amount of cognitive time and energy required to deliver multiple decisions. Once the project manager has made the initial investment to learn this tool for one complex decision, the same tool can be re-used both in subsequent decisions and in other projects.

The current study presents an Expert Choice model to illustrate how risks can be prioritized as part of a project risk quantification activity. Project risk management consists of four processes. (Project Management Institute Standards Committee 1996):

(1) Identification

(2) Quantification

(3) Response Development

(4) Response Control

During the Quantification process, each risk is assigned an estimated probability and an estimated impact. The probability is the likelihood, based on currently-available information, that the risk event will occur. The impact is the percentage of the total project value that will be lost if the risk event occurs. Quantitative estimates of both criteria are elicited from experts and recorded during this phase.

These results are used to prioritize the identified risks in order of severity from highest to lowest. Highimpact, high-likelihood risks would receive top priority for developing mitigation, deflection, or avoidance strategies. At the other extreme, low-impact low-likelihood risks are typically just accepted by the project; workarounds are developed if and when they materialize.

Expert Choice provides a convenient and consistent scheme for recording impact and probability estimates and displaying relative rankings. Sample results are displayed in Figure 1 using the "2D Plot" Sensitivity Graph. Risk 1 is estimated to have a relative probability of 29 and a relative impact of 13 . Risk 2 has corresponding estimates, respectively, of 18 and 33, and the estimates for Risk 3 are 53 and 54.

In this example, Risk 3 is the top-priority, with a combined raw score, probability plus impact, of 1.06, and a score relative to the other risks of $53.1 \%$. Risks 1 and 2 are substantially lower, with combined raw scores of 0.43 and 0.51 , respectively, corresponding to relative scores of $21.4 \%$ and $25.5 \%$. These scores are reflected in Figure 2 using the Dynamic Sensitivity Analysis mode in Expert Choice.

Note that absolute probability and likelihood estimates are not required to drive the quantification process. Relative values are sufficient to provide rank ordering. Once all major risks have been identified and 
quantified, estimates of absolute magnitudes can be made. These estimates can help determine how deeply down the priority list the project team should reach in developing response strategies.

As the project entered the execution and control phase, additional information would become available. At this point the existing models could readily be refined to include new probability and impact estimates.

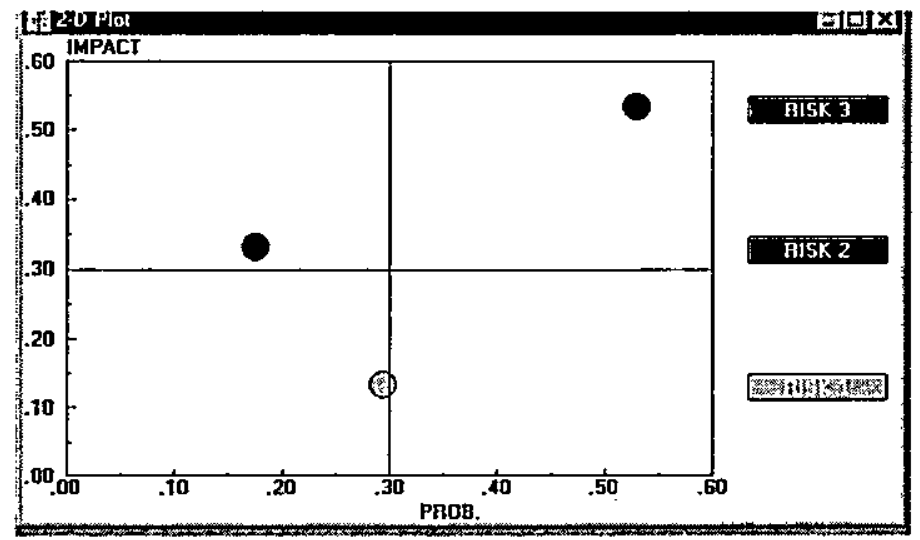

Figure 1 Relative Probability and Impact Assessments (2D Display)

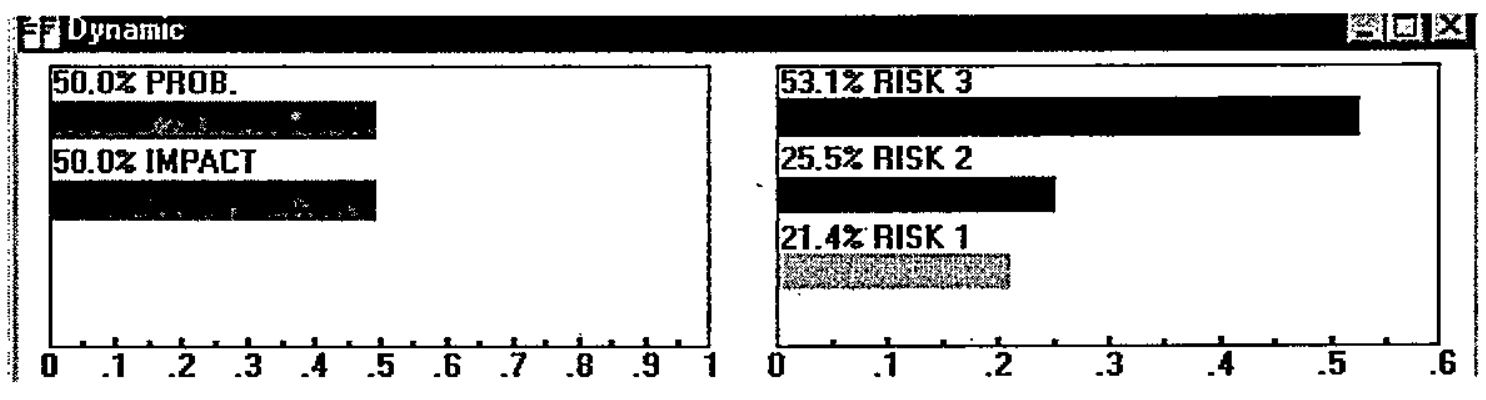

Figure 2 Relative Probability and Impact Assessments (Dynamic Sensitivity Analysis Display)

\section{References}

Forman, E. H., Saaty, T. L., Selly, M. A., and Waldron R. (1996) Expert Choice, Decision Support Software, Inc., McLean, VA

Mian, S. and Dai, C. X. (1999), "Decision Making Over the Project Life Cycle: An Analytic Hierarchy Approach", Project Management Journal, March, 30:1.

Project Management Institute Standards Committee, (1996) A Guide to the Project Management Body of Knowledge $\left(P M B O K^{7 M}\right)$, Project Management Institute, Newtown Square, PA 